\title{
The Production and Reception of the Two Adapted Versions of Manhunt
}

\author{
Chenyixuan Xiao ${ }^{1, *}$ \\ College of Foreign Languages, Hunan Institute of Engineering, Xiangtan, Hunan Province, 411100, China. \\ *Email: chenyixuanxiao@hnie.edu.cn
}

\begin{abstract}
Japanese hard-romantic detective novelist Juko Nishimura's representative work, Manhunt (Kimiyo funnu no kawa wo watare), was adapted twice in history: Junya Sato's You Must Cross the River of Wrath/Manhunt in 1976 and John Woo's Manhunt in 2017. This article analyzes the differences between the two films based on filmmaking skills and text analysis and compares the reception of the two films in terms of box office and criticism from a cross-cultural perspective. It finds out that the 1976 Japanese version, which faithfully respects the dominant role of the novel author in the story, brings great Japanese cultural power to China, while the 2017 version, a multinational co-produced film that embodies the film director's authorship, fails to achieve cross-cultural reception. Thus, the article is useful to provide a reference for the cross-cultural adaptation of classic literary works.
\end{abstract}

Keywords: Manhunt, Cross-culture, Film Production, Film Reception, Film Adaptation.

\section{INTRODUCTION}

In the 1970s, the Japanese hard-boiled detective fictionist, Juko Nishimura, launched his masterpiece Manhunt (Kimiyo funnu no kawa wo watare). The novel tells the story of how a tough prosecutor clears his name while avoiding the police chase after being falsely accused of rape and pilferage. This book was adapted twice in 1976 by the Japanese director Junya Sato, Manhunt (AKA You Must Cross the River of Wrath, Dangerous Chase, Hot Pursuit), and the other is Manhunt remade by Chinese action film master John Woo in 2017. What are the differences in the production and reception of the two films adapted from the same novel? What lessons can we learn from the two films about film adaptation? Auteurism holds that the film director is a creator with the same status as the novelist. Since Alexandre Astruc put forward the camera-style/ camera-pen in Birth of a New Avant-Garde: CameraPen in 1948, the film director is no longer a servant of the existing text but a creative artist [1]. François Truffaut further proposed that the director can create his own style and theme in the film in his interpretation of authorship [1]. The director has creative freedom when adapting a novel into a movie based on the differences between the two art forms and the director's style. Desmond and Hawkes [2] point out that the film needs to be tailored, merged, and rearranged in terms of plot, characters, dialogue, and scenes when adapting a novel. Different adapting strategies from novels into movies can be distinguished for distinctive purposes based on the comparison between novel and film text. The value of adapted movies should not be judged based on whether they are faithful to the original. Currently, studies on the two film versions of Nishimura Juko's Manhunt are rather few. The study of the 1976 film version mainly summarizes its huge cultural influence on Chinese society in 1978 [3-4], and the articles on the 2017 version approve of John Woo's gun-fu style in the film [5-6]. Chinese scholars have pointed out the insufficiency of Woo's version in the depth of the theme, the coherence of the story and the motivation of the protagonist, and even the confusion in the performance style and aesthetic motifs [7-9]. However, no article has studied the production and reception of the two films to examine the process and products of different film adaptation strategies.

This article aims to comprehensively analyze the production and reception of the two films from filmmakers' perspectives, film text, and audiences, to provide a reference for cross-cultural adaptation of classic literary works. The 1976 version faithfully conveys the plot and theme of the original novel, producing a significant cultural influence in China during its Reform and Opening-up period by introducing the modern life and judicial system in Japan. 
The co-produced 2017 version was away from the original in plots, characters, and motifs. Although it reassures Woo's authorship developed in his gun-fu heroic films, it neither transcends the high-quality old film version nor reinterprets the novel themes in the new century. The comparison of the two films reveals that in the cross-cultural adaptation of classic novels to films, a successful adapted film can actually exert a significant cultural influence in other countries when it is produced by the director and actors from the original novel's culture and loyally delivers the novel's themes and story. However, when the film is made by a director from another culture, co-produced by actors from different countries, and replaces the author's style with the director's authorship, it will be difficult to convey the charm and cultural power of the original work.

\section{PRODUCTION}

\subsection{Juko Nishimura \& Manhunt}

Juko Nishimura (1930-2007), born in 1930, was one of the richest and most popular crime and adventure novelists in Japan from the 1970s to the 1980s. Before becoming a writer, Nishimura worked as a news reporter, taxi driver, fisherman, restaurant owner, and more than twenty different jobs [10]. With a preference for wild animals and hunting knowledge, his debut work in 1976 was an animal novel, Inuwashi (Golden Eagle). Nishimura wrote more than one hundred novels in his life. Other representative works include Anrakushi (Euthanasia), Hoko wa kieta (Roar Was Disappeared), and Horobi no fue (Flute of the Destruction), which are featured by violence, blood, sex, adventure, and revenge. His stories revolve around the male protagonists who are forced into desperation, fight against fate and go through hardships to expose the darkness of social reality [10].

In 1974, Juko Nishimura began to write Manhunt, which was published next year in the magazine Problem Novels by Tokuma Shoten Publishing company. The story is about Morioka, a prosecutor from the Tokyo Prefectural Police. He was charged with rape and pilferage and forced to embark on an escape journey. From Tokyo to Hokkaido, he wrestles with a brown bear in the forests, learns to fly a plane to cross the sea at night, investigates a mental hospital, and fights with sharks in the dark sea. He meets diverse people along the way, including the elderly who hates the government, the convenience store clerk who struggles with the unfair world, the tramp who adores his wife but flees the family, and a prostitute who longs for true love. From a respected elite prosecutor to a displaced fugitive, the subversion of social status and the degradation of social class allow Morioka to observe the injustice in legality and witness the shadow in the medical industry, prompting himself to examine the value of life and the duty of a prosecutor. Physical and mental hardships compel him to realize that both the past and the future are beyond his control. Thus he can only live in the moment. As the role of people will constantly switch between the hunter and the prey in real life, he concludes from his experience that only the hunter can take the initiative.

\subsection{The 1976 Film Version of Manhunt}

The novel Manhunt gained popularity overnight in Japan. Nagata Productions and Daiei Studios invited Ken Takakura to star Morioka to adapt the novel into a film. Takakura is tall and strong with a poker face. His appearance rather matches Morioka's image of a tough guy in the novel. The heroine is Ryoko Nakano. Kunie Tanaka, famous for playing supporting roles, played Keiji Yokomichi, who accused Morioka of pilferage in the story. The film director is Junya Sato (1932-2019), a Japanese film director and screenwriter. Graduated from the University of Tokyo, he directed more than thirty Japanese movies and seven TV series from the 1960s to the $21 \mathrm{st}$ century. Manhunt becomes one of his representative works. According to a documentary about the film [11], Sato was very concerned about the relationship between individuals and the country as he experienced wartime periods. Therefore, his Manhunt is a reflection of how the country sacrifices individuals to cover up its mistakes.

Manhunt, the 151-minute-long film, was produced in six months and had a budget of 500 million yen (according to its poster). Based on Nishimura's original work, screenwriter Kei Tasaka adapted the script. Hachiro Aoyama was asked to create music based on the script instead of the film [11]. He used the guitar to express suspense and jazz instead of classical music to express love. The theme song, Lonely Escape, hummed by the male voice, is fast-paced and full of passion.

Manhunt faced many difficulties in production. One important scene is Morioka driving a CESSNA-JA3611 (the plane type is CESSNA-177 Cardinal in the book version [12]) aircraft given by Mayumi's father to escape. The plane was borrowed from a friend of the producer and was piloted by Takakura himself in the film[11]. Another difficulty was the shots of horse racing in Shinjuku, which was also the film's main selling point. Sato needs to obtain the police's permission and have horses. In the story, when the police chase Morioka on the streets of Shinjuku, Mayumi arrives with a group of racing horses covering the two to flee away.

The 1976 version retains the settings of the main characters, including Morioka, Yamura, Mayumi, and the Yokomichi couple. The film also follows the storyline, reproduces the fight in the forest, the flight at 
night, the secret mission in the psychiatric hospital, but with the following important changes:

(1)The hunter in the forest was deleted;

(2)The research institute scenes and Morioka's fight with sharks in the sea were deleted;

(3)The ending of the enemies were added to the story;

(4)Sakai had additional two followers who killed Yokomichi Kayo and chased Morioka;

(5)Mayumi acts as an important heroine to drive the plot.

The difference between film art and literature makes it difficult to deliver every word from the story in adaptation, even if the film is faithful to the original work. Therefore, the novel's content needs to be appropriately edited considering the length and space of the film. The 1976 version of Manhunt retains most of the original narrative elements in adaptation. It simplifies the story and reduces characters but makes the overall plot more coherent and complete by adding the two killers in the storyline, strengthening Mayumi's role in the story, and giving the finale for the main characters in the story. As the original work is a toughman story, the film version especially designs the emotional scenes between Mayumi and Morioka, adding to the romance of the film. The Shinjuku racing scenes between Morioka and Mayumi bring great emotional appeal to both original novel readers and viewers who have never read the story.

Meanwhile, the filmmaking technologies help to demonstrate the story's artistic charm, which is hard to show in the novel. For example, the film uses blackand-white flashbacks or red flashing shots to distinguish Morioka's memories from reality. Those flashback shots, the frequently inserted newspaper headlines, and TV news, are especially beneficial for the plot coherence and audience understanding in a long film. Besides, the passionate electronic background music, the fashionable clothing, and high buildings with modern facilities help to highlight the theme: the importance and necessity to constantly reflect on the social system and the man-state relationship in the fastdeveloping Japanese society.

Centered on Morioka's sole experience in the escape, the film triggers the reflection on the relationship between the hunter and the prey, the collusion between the government and the medical industry, and the deficiency of the present judicial system. In general, Junya Sato's version is loyal to the story of the original novel. Such adaptation can both satisfy the original novel readers and promote the story to ordinary audiences. Nevertheless, it is noticeable that the entire film length is about 2.5 hours, which places high demands on the cinema-goers' patience and attention.

\subsection{The 2017 Film Version of Manhunt}

Media Asia Film Production Company produced the 2017 film version of Manhunt. It was shot and produced in 2016, mostly in Osaka, Japan. The 106-minute-film uses Mandarin, English, and Japanese as mixed dialogues and casts actors and actresses from China, Japan, and Korea. The Chinese mainland actor Hanyu Zhang (from Zhang Yimou's The Great Wall in 2016) played Du Qiu (transliterated from the Chinese pronunciation of Morioka), and the mainland actress Wei Qi played Mayumi. The film retains the two killers from the 1976 version, and they are named Rain (South Korean actress Ji-won Ha) and Down (John Woo's daughter Angeles Woo). South Korean actor Byung-hun Lee missed the villain because of a scheduling conflict. The Japanese play the rest characters: the parallel hero Yamura is played by the actor and singer Masaharu Fukuyama, and the enemy Sakai is played by Jun Kunimura. Kunimura gained famous in Quentin Tarantino's Kill Bill: Vol. 1 (2003) and played in John Woo's last Hong Kong action film Hard Boiled (1992) before Woo left for Hollywood.

The director of the new version is John Woo (1946), a well-known action film master from Hong Kong, China. His films are famous for the bloody and violent scenes, the slow-motion fights, the rainy and densely resounding bullets, the contrasting three colors of black, white and red, and the heart-touching brotherhood and dominating masculinity, which constitute his distinctive authorship in a series of heroic films like $A$ Better Tomorrow I \& II (1986,1987) and The Killer (1989) from the 1980s to 1990s. After he set sail in Hollywood, Face/Off (1997) and Mission: Impossible II (2000) helped him gain both worldwide recognition and financial success in Hollywood. At the 2015 Cannes Film Festival, Woo said that he would remake Manhunt to pay tribute to Ken Takakura, who greatly inspired his action classics like The Killer and Hard Boiled (1992) [13].

The 2017 film version of Manhunt embodies a tribute to the 1976 version. The film quoted the classic dialogues from the 1976 version both at the beginning and the end of the film, and Morioka hummed Lonely Escape from the 1976 version to evoke the audience's memories of the classic story. However, overall, the 2017 version shows great differences from both the original novel and the 1976 film in characters, plots, and motifs.

The 2017 version has removed some characters changed almost all the settings:

(1)The supporting roles including the Yokomichi couple, the prostitute, and the hunter were deleted;

(2)Mayumi's father was deleted and she had a fiancé, whose death drives her to pursue the truth; 
(3)The apartment guard and the homeless man were merged into a new role;

(4)Sakai had a son, who is impulsive, reckless, and violent;

(5)In the previous version, Sakai's two male killers changed to two female professional killers, Down and Rain;

(6)Yamura's male assistant in the 1976 version was replaced by a female role. The pattern of a clumsy but loyal female assistant and an experienced and capable detective in the film references Fukuyama's Galileo series $(2007 \& 2013)$.

The 2017 version of Manhunt greatly changed characters' settings to rationalize the foreign actors in the Japanese story and continue the parallel hero model in his heroic films. Du Qiu became an international attorney from China with surprisingly good kung fu and shooting ability. Yamura shows a strong desire for communication and understanding instead of reticence and stubbornness in the previous film version. The emotion between Mayumi and Du Qiu is almost deleted, and so is the Shinjuku horse scene, thus greatly diminishing Mayumi's courage and passion in the story. Woo also changes the supporting roles to adapt the revenge story of a lonely hero into a comic story against evil forces by gathering justice partners. The empowered women with guns are deeply involved in the storyline, rather than being marginalized in the conventional Hong Kong action genre.

The main line of the story has also changed drastically. In the new version, the story stage was set in Osaka instead of Tokyo and Hokkaido. The Sakai Group developed a new illegal drug and traded it with the military and terrorists to gain benefits. The boss Sakai expelled the company's beautiful secretary to seduce Du Qiu, hoping him continue serving the business because he knew too many secrets. Sakai's son accidentally killed the woman out of jealousy and anger and framed Du Qiu for the murder. Thus, Du Qiu was forced to escape. He was involved in many gun battles with Sakai's two killers Down and Rain. Down died of an overdose of the dangerous medicine, prompting Rain to choose to betray Sakai. In the fight at the research institute, Du Qiu, Yamura, Mayumi, and Rain defeated Sakai and his son together.

The original novel centers on two prominent questions: 'who frames Morioka?' and 'why do they frame Morioka?'. The search for the truth guides readers to step on the lonely journey with Morioka in the story. In the 1976 film version, the answers to the two questions have not been revealed until the last 20 minutes of the suspense. On the contrary, the 2017 version adapted by seven playwrights shows the Sakai gang and implies the illegal medicine at the film's beginning. Then the story's appeal has become the action scenes instead of the suspense feelings and social reflection.

In terms of the film motifs, the 2017 version neither transcends John Woo's Hong Kong films nor outperforms the original film. John Woo's previous heroic films imply the confusion under the background of Hong Kong's return, the nostalgia, and the emphasis on masculinity and brotherhood. The theme of the 2017 version of Manhunt inherits Woo's previous films to focus on the brotherhood between parallel characters. The ending dialogue of Yamura, "for a better tomorrow," even echoes the title of Woo's representative action films, the A Better Tomorrow series.

However, it simplifies the novel's motif to the battle between good and evil. Both the original story and the 1976 version portray the despair in Morioka's lonely escape and reflect on the commitment and deficiencies of the judicial system. In the 2017 version, Du Qiu, as a foreign attorney who is away from the Japanese judicial system, cannot reflect on the Japanese social problems. Moreover, the setting of parallel heroes weakens his loneliness in despair. Thus it is difficult to inspire the audience's empathy or reflection.

The 2017 film reflects Woo's authorship but drastically revised the storyline, character settings, and themes. Unlike the close connection between the original novel and the 1976 version of Manhunt, the 2017 version is loosely connected with the original novel. The simplified story in the 2017 version diminishes the depth of the original theme, and the male bonding between the parallel male protagonists fails to achieve the heterosexual emotional effect between Morioka and Mayumi in the 1976 version.

Based on the author theory, there will be two authors when adapting a literary classic into a movie. The 1976 version follows the dominant position of the novel author, while the new version is more embodied as a Woo-style action film. The new version can surely promote the popularity of Juko Nishimura's novel. Still, it is difficult for the audience to appreciate the charm of the original work because of the deviation of the theme and the large-scale adaptation of the narratives.

\section{RECEPTION}

\subsection{Release}

\subsubsection{The 1976 Version of Manhunt}

Junya Sato's Manhunt was released in the cinema in February 1976 and on TV in January 1979. According to Sato [11], there were not many audiences when it was first shown in Japan. However, after it gained popularity in China, it attracted more Japanese audiences and made some profits. 
In 1978, Manhunt was screened at the Japanese Film Week held in Beijing that year to commemorate the Sino-Japan Treaty of Peace and Friendship Treaty [7]. When it was released, some people lined up for 3 days to buy film tickets, and some people watched 54 times of the film. According to a Japanese NHK Broadcasting Culture Research Institute survey in China in October $1999,80.2 \%$ of the survey respondents had watched Manhunt [9].

When Manhunt was introduced to China, it was dubbed by Shanghai Dubbing Studio. Zhen Qiao was the dubbing director, $\mathrm{Ke} \mathrm{Bi}$ dubbed Morioka, and Jianhua Ding dubbed Mayumi. According to a Chinese scholar Lin's record [3], Junya Sato's Manhunt was edited from 151 minutes into 112 minutes. A total of 39 minutes and 15 seconds were cut out, mainly including the following deleted 6 scenes :
(2)Morioka and Mayumi spent a night in a cave in Hokkaido ;

(3)Morioka beat a ranger on the way back to Tokyo as the man recognized and prepared to shoot him;

(4)Morioka was rescued by a woman and stayed at her home overnight ;

(5)Mayumi stripped naked to drive off Yamura at the hotel ;

(6)Morioka clarified to the chief prosecutor that he would not return to his position after he knew the truth.

Lin believes that these cuts were necessary when the film was introduced into China in a transitional period. Although they subtly changed the film's main theme, they were conducive to shaping the ideal man and woman to meet the expectations of Chinese audiences.

(1)Morioka stole the shoes of the temple pilgrims;

Table 1. The data of general reviews on Manhunt (1976) and Manhunt (2017)

\begin{tabular}{l|l|l|}
\hline Items & Manhunt (1976) & Manhunt (2017) \\
\hline $\begin{array}{l}\text { Audience Score } \\
\text { (from China's Douban.com) }\end{array}$ & $\begin{array}{l}8.2 \text { out of } 10 \\
\text { (Better than 90\% crime movies, 93\% } \\
\text { action movies) }\end{array}$ & $\begin{array}{l}\text { (Better than 6\% crime movies, } \\
\text { 2\% action movies) }\end{array}$ \\
\hline $\begin{array}{l}\text { Audience Viewing Number } \\
\text { (from China's Douban.com) }\end{array}$ & 25135 & 30797 \\
\hline $\begin{array}{l}\text { Audience Score } \\
\text { (from Yahoo! JAPAN) }\end{array}$ & 2.97 out of 5 & 2.78 out of 5 \\
\hline $\begin{array}{l}\text { Audience Rating Number } \\
\text { (from Yahoo! JAPAN) }\end{array}$ & 224 & 1457 \\
\hline
\end{tabular}

\subsubsection{The 2017 Version of Manhunt}

John Woo's Manhunt was distributed by Media Asia Film Distribution $\mathrm{HK}$ and released in China and Malaysia in 2017. In 2018, the film was released in Japan and South Korea. In Hong Kong, the first round of cumulative box office in Hong Kong was 2,765,535 Hong Kong dollars, ranking 20th among 53 movies in the year [14]. With a total box office of 16 million dollars in mainland China, it ranks 13th among Hong Kong films released in the mainland and 87th among all films released in the mainland in 2017. According to Box Office Mojo data [15], the film has a box office of around 2 million US dollars in Japan and 20,166 US dollars in South Korea. The total worldwide box office was about 18 million US dollars.

\subsection{Reviews from General Public}

The ratings of two versions of Manhunt on the Chinese largest film forum Douban.com [16-17] and the Japanese popular forum Yahoo! JAPAN [18-19] are collected to compare the general comments on both films. As shown in the table below, for the two versions of the film, the number of online reviews in China far exceeds that of Japan. Indeed, both the Chinese reviewers' number and their ratings for 1976 are surprisingly high. When it comes to scoring, the ratings given by the Chinese and Japanese audiences are very different. Japanese audiences show less difference in evaluating the Japanese version and the transnational version. However, the evaluation of Chinese audiences is polarized. The Japanese audience gives the two films scores of 2.97 and 2.78 out of 5 , respectively, while the Chinese audience gives the 1976 version a high score of 8.2 out of 10 . As to the new version, Chinese audiences expressed their disappointment with John Woo and attributed the deficiencies of the film to the following points:

(1)The casting was disappointing;

(2)The character's motivation was unclear, the story lacked logic, and the narrative rhythm was intermittent; 
(3)In the fierce gun battle, Morioka, Yamura, and Mayumi could never die while others die easily;

(4)The mixed three languages of dialogue (Chinese, English, and Japanese) distracted viewers from the story.

(5)The white pigeons, bullets, bombs, car chase, and parallel heroes could signify Woo's action style but the new version lost the serious motifs of the original novel.

Chinese audiences show great enthusiasm towards both versions of Manhunt. They appreciate the 1976 version as it triggers the reflection on society and shapes the ideal man and woman with Morioka and Mayumi. On the other hand, they are dissatisfied with the large deviation between the 2017 version and the original novel.

\subsection{Reviews from Critics}

\subsubsection{The 1976 Version of Manhunt}

Among the Japanese films released from the 1970s to the 1980s, Manhunt was neither the most successful nor the most representative work in Japan [7,11] However, it became a typical example that had a mediocre response at home but became a classic in other places as it greatly inspired Chinese audiences in the last century [8]

During the 1970s, with the normalization of diplomatic relations between China and Japan in 1972 and the end of the Chinese Cultural Revolution in 1978, China entered into a new era of reform and opening up. As a result, Japanese films such as The Izu Dancer (1974), The Yellow Handkerchief of Happiness (1977), and other Japanese films entered the Chinese market on a large scale. Manhunt (1976) was also released in the mainland of China and was warmly welcomed by the public.

Manhunt (1976) is a qualified Japanese-style thriller. The film enriched people's aesthetic values and introduced people to modern Japanese society. During the Cultural Revolution from 1966 to 1976, revolutionary model operas, including The Legend of the Red Lantern (1971), Sha Jia Bang (1971), Taking Tiger Mountain by Strategy (1970), Raid on the White Tiger Regiment (1972), The Red Detachment of Women (1971) and The White-haired Girl (1971) took the mainstream in the Chinese art market. These films mainly revolved around the armed struggle and economic construction carried out by the people under the leadership of the Communist Party of China. Except for those propaganda materials, there were only some news documentaries and a few socialist countries' films [4] In this context, the newly introduced Manhunt contrasted with the prevalent model dramas and documentaries with its wonderful storyline and modern filmmaking skills. The typical Japanese detective story retained a sense of suspense[8]. The setting, costumes, props, photography, lighting, and music all innovated people's understanding of film art and broadened the people's single aesthetic vision [4] Also, the film has changed people's image of modern Japan through Japan's bustling streets, characters' fashionable dresses, and a hierarchical but humanistic bureaucracy [4]

Chinese society ended the Cultural Revolution and redressed unjust, false, and wrongful cases from the late 1970 s to the early 1980 s. Under the background of this special period, the film successfully aroused emotional resonance among people. Focusing on the theme of 'hunting and being hunted', the film was about the story of Morioka struggling to pursue the truth after being trapped. Such a story could trigger the Chinese people to reflect on the past ten years of the revolution at that time. The film also surpassed the traditional aesthetic convention of absolute good and evil by blurring their boundaries and providing the hunted people with the right to defend themselves [4] Chinese writer Fayun $\mathrm{Hu}$ recalled the popularity of Manhunt in the mainland of China in a memorial essay to his deceased wife and compared Morioka and Mayumi's feelings with his and his wife's painstaking memories [20]. He highly appreciated the two characters' mutual understanding, trust, support, and courage to pursue the truth.

The modern-dressed and distinctive characters are impressive. Instead of preaching characters in model operas, the characters portrayed in Manhunt have distinctive personalities and modern dresses. After Ken Takakura shaped the image of an ideal man (tall, silent, cold, and tough) and Ryoko Nakano exemplified an ideal woman (sincere, beautiful, and independent), Chinese young people began to imitate their dressing from wind coats, sunglasses to hairstyles. These leading actors even became a bridge to promote friendly exchanges between China and Japan. In 1979, when Ryoko Nakano visited China, she was overwhelmed by Chinese people's passion and everyone's calling, 'Mayumi'. In 1986, Ken Takakura, Ryoko Nakano, and Kunie Tanaka visited China's Beijing Film Academy as the Japanese film delegation members. The film director Junya Sato also visited China and shot films such as The Silk Road (1988) after the popularity of Manhunt.

Particularly, Ken Takakura had a profound influence on Chinese movies because he reshaped the ideal male image on the screen, as mentioned before. According to the Chinese actor Guoqiang Tang, the successful performance of Takakura in Manhunt aroused serious public criticism of himself, who was regarded as a representative good-looking but not a mannish young actor [21]. Takakura not only inspired a group of famous tough filmmakers such as Wen Jiang, Fengyi Zhang, You Ge in the film industry [22], but also influenced the fifth generation of Chinese directors, namely the students who graduated from the Directing 
Department of Beijing Film Academy after 1982. Zhuangzhuang Tian once interviewed Takakura in 1995, and Yimou Zhang invited him to lead Riding Alone for Thousands of Miles (2005). Changwei Gu also played the scene of Mayumi's confessing to Morioka on television in Peacock (2005).

Manhunt also inspired a series of thrillers in China, like Murder In 405 (1980), The Prosecutor (1981), and The Passenger in Handcuffs (1981) [3]. In addition, in 1987, Shanghai staged a play called Looking for Mr.Right, which was later adapted into a movie by the director Xueqiang Zeng in 1987. The heroine in the play struggled to find a real man, which referred to the image of Ken Takakura in Manhunt.

In short, the Japanese film Manhunt has a far more profound influence in China than in Japan, fully demonstrating the success of the 1976 version in crosscultural communication. The shaping of characters on the screen and the mature filmmaking skills injected new vigor into the Chinese film industry and promoted the modernization of film aesthetics and film language after the Cultural Revolution. The film also changed people's aesthetics of males and females and refreshed their understanding of love. Further, the film's success advanced the continuous friendly cultural exchanges between China and Japan in film art.

\subsubsection{The 2017 Version of Manhunt}

Many critics agreed that the new version of Manhunt is a return of John Woo's gun-fu style and some of them paid great attention to the following three aspects.

The return of Woo's action film. This film is considered to review the patented bloodshed style formed by Woo's heroic films from the 1980s to the 1990s [13], especially very similar to The Killer [6]. White doves, broken glass, bullets and explosions, slowmotion battle scenes, car chases, and gun battles all compose the authorship of the Hong Kong action film master.

A cartoonish film. Some critics identify the comic feel of the film. Young argues that the protagonists are similar to comic heroes as they can never be seriously injured in the bullets rain [6]. Romney believes that the dangerous medicine is Marvel style, and the research laboratory in the final scene is 'the traditional Bond villain lair' [5]. Hong Kong film critic Xing claims that the conspiracies in the story are all in the style of animation and video games [8].

The unstable homosocial bonding. Woo's Hong Kong heroic films are famous for their emphasis on the homosocial bonding between male characters. In Manhunt, Woo sets two homosocial partners: Du QiuYamura and Down-Rain. However, Xing suggests that the female bonding between the two killers seems more impressive than brotherhood [8]. Fei points out that Rain's affection for Du Qiu causes instability in the homosocial structure [9]. Mayumi seems to be independent of the two homosocial groups, even if she is the heroine. Zheng regards the emphasis on female bonding in Woo's film adapted from a hard-boiled novel as unbelievable [7].

Critics have mixed reviews towards the new Manhunt. Romney praises the new version for its' breezy, handsomely mounted fun' [5]. In addition, he praises that the film, as Woo's first Asian police thriller since Hard Boiled (1992), for its introduction to Woo's gun-fu genre to the young fans of modern action films and consolidate Woo's international status as an auteur director.

However, some critics, especially critics from China, point out the film's inadequacies, especially regarding the plot and characters. The storyline of the 2017 version has been substantially changed, but the characters' behaviors lack logic, and the motif is not deep enough. As a co-produced film, the new Manhunt has actors and actresses from China, Japan, and South Korea and changes the corresponding character settings. The new story has a Chinese lawyer Du Qiu, the SinoJapanese hybrid Mayumi, and English-speaking Asian killers Down and Rain. However, the changed character settings have not been explained clearly enough and fail to effectively and coherently drive plots development [9], except for the mixed dialogues. Du Qiu's Chinese identity even restricted him from exploring the mountains like Morioka in the original novel. As a result, there is no clear set of other places except Osaka in the new version [8]. Besides, Yamura, as the parallel hero, has a young female policewoman to work with. Zheng implies that the setting follows the policedetective pattern in Masaharu Fukuyama's past criminal films, but their emotional interaction interferes with the main plot [7]. In the 1976 version, Mayumi's affection for Morioka is the essential emotional clue and brings the two exciting and moving horse scenes in Hokkaido and Shinjuku. It is a pity to miss those scenes in the new version as Mayumi is no longer desperate for Morioka regardless of her father's political status and even her own life.

The 2017 story was also evaluated for lack of depth and suspense feelings compared with the original novel. Xing points out the lack of suspense [8] and Fei summarizes that the motif of the new version is to expose the plots of the outlaw medicine companies instead of the rigid state machines, the corrupt government official, and the unscrupulous hospitals [9]. As a result, Woo's Manhunt largely weakened the criticism of the social darkness in comparison with the original novel.

Zheng comments on the 2017 Manhunt with the consideration of the film industry in China [7]. He refers 
to major commercial blockbusters such as Operation Mekong (2016) and Wolf Warriors 2 (2017). He owes their success to combining the high-quality Hong Kong film genres with China's ideological values. In this context, he praises John Woo's adherence to his own authorship. Still, he points out Woo's hesitation towards film adaptation, as it fails to reflect Woo's international visions and values in the new century. To be more specific, Du Qiu in the film cannot reflect the courage and responsibility a Chinese in Japan should have when facing difficulties and challenges but troubled in endless fierce gun battles. Moreover, the hybrid genres and fragmented stories presented in the movie make it difficult to meet the tastes and requirements of the current market.

In summary, the 2017 version reproduces John Woo's action film style in the new century. Woo adds female characters and female bonding to refresh his aesthetic themes. Still, femininity occupies the showing space of masculinity in scenes and plots, and the heterosexual interactions interfere with the homosocial bonding, leading to the chaos of the aesthetic themes. Also, the co-production model of multinational actors and the drastic modification of plots, roles, and themes have affected the cross-cultural spread of Japanese culture delivered by the original story.

\section{CONCLUSION}

From production and reception, this article reviews the two films adapted from Juko Nishimura's novel Manhunt in 1976 by Junya Sato and in 2017 by John Woo. The two films reflect great differences in filmmaking, film texts, box-office, and reviews. The original novel tells the story of prosecutor Morioka trying to find the truth after being framed. During the escape journey, he constantly reflected on the Japanese judicial system, the medical system, and even the social class, mirroring the author Nishimura's thinking about Japan's society. Sato Junya's adaptation is closely related to the original, but he supplemented the plot and added characters to make the story more coherent, concise, and complete. As a successful case of crosscultural transmission, the 1976 version gained great popularity in China. It influenced the Chinese film industry and inspired the Chinese people who just experienced the Cultural Revolution and began to reform and open up in the 1970s. John Woo's remake in 2017 is a co-produced film by actors from different countries. It greatly changes the characters, plots, and themes of the original story. With the iconic white doves, the slow-motion gun battles, car chases, the strong rhythm of the pictures, the almost abusive special effects, and the tough and experienced parallel protagonists, this film constitutes Woo's gun-fu world and consolidates his authorship developed from the mid1980 s to the early 1990 s. However, the simplified motif, the weakened masculinity and the threatened brotherhood made the film hard to arouse Chinese people's emotional resonance in fast-growing China in the 21 st century. Therefore, in cross-cultural adaptation, the production team and the delivery of the original story are two important factors that need to be taken into consideration. The film produced by the local team and conveys the original story, themes, and artistic styles can better introduce the local culture to other countries. When the foreign filmmakers lead the film adaptation from a novel and greatly change the story, the culture and ideas of the original work will be difficult to reach the foreign audience in a cross-cultural context.

\section{REFERENCES}

[1] R. Stam, Film Theory: An Introduction, Peking University Press, 2017.

[2] J.M. Desmond, P. Hawkes, Adaptation: Studying Film and Literature, World Publishing, 2016.

[3] T. Lin, Manhunt and the Chinese Reception in the 1970s, Journal of Japanese Language Study and Research, 04, 2010, pp. 29-35. DOI: 10.13508/j.cnki.jsr.2010.04.015

[4] J. Wei, The Secretes of "Hunting Hearts"Analysis of the Popularity of Manhunt in China, New Century Theater, 04, 2018, pp. 69-76. DOI: 10.13508/j.cnki.jsr.2010.04.015

[5] J. Romney, Manhunt: Venice Review. Screen Daily. 2017. Available at: https://www.screendaily.com/reviews/manhuntvenice-review/5122041.article (Accessed: 21 September 2021)

[6] D. Young, Manhunt: FilmReview, The Hollywood Newspaper, $2017 . \quad$ Available at:https://www.hollywoodreporter.com/movies/mo vie-reviews/manhunt-1038671(Accessed: September 2021)

[7] Y. Zheng, Perseverance and Chaos, Chinese Art, 08, 2017, pp. 1-2. DOI: 10.28155/n.cnki.ncysb.2017.000178

[8] G. Xing, Manhunt: Gunfight, Takungpao, 2017. Available at: https://www.filmcritics.org.hk/filmreview/node/2018/05/09/Manhunt (Accessed: 21 September 2021)

[9] N. Fei, Manhunt: Regional Cooperation and Aesthetic Chaos, China Film New, 002, 2017. pp.1-2. DOI: 10.28064/n.cnki.ncdyb.2017.000010

[10] W. Feng, Juko Nishimura: The "Predator" of Violence and Sex, Qianjiang Evening News 21, 2007, pp. 6. 
[11] Legends of Films: Manhunt - - Morioka and Mayumi, CCTV 1, 28 July, 2007.

[12] J. Nishimura. You Must Cross the River of Wrath, Newrain Publishing, 2017.

[13] C. Coonan, Cannes: John Woo on Returning to His Roots With Manhunt Reboot (Q\&A), The Hollywood Newspaper, 2015. Available at: https://www.hollywoodreporter.com/movies/movie -news/cannes-2015-john-woo-returning-795320 (Accessed: 21 September 2021)

[14] Hong Kong Film Industry Report 2017, Hong Kong Motion Picture Industry Association, (no date). Available at: https://www.fdc.gov.hk/tc/press/publication.htm. (Accessed: 21 September 2021)

[15] Manhunt 2017, Box Office Mojo. Available at: https://www.boxofficemojo.com/title/tt4537986/?r ef_=bo_se_r_1 (Accessed: 21 September 2021)

[16] Manhunt 1976, Douban Movie. Available at: https://movie.douban.com/subject/1291863/(Acces sed: 21 September 2021)

[17] Manhunt 2017, Douban Movie. Available at: https://movie.douban.com/subject/26348414/ (Accessed: 21 September 2021)

[18] Manhunt 1976, Yahoo, Japan. Available at:https://movie.douban.com/subject/26348414/ (Accessed: 21 September 2021)

[19] Manhunt 2017, Yahoo, Japan. Available at:https://movies.yahoo.co.jp/movie/362548/ (Accessed: 21 September 2021)

[20] F. Hu, Manhunt and Me in 1978, Nanfang Weekend, 2014. Available at: http://www.infzm.com/contents/106426 (Accessed: 21 September 2021)

[21] The 40th Anniversary of Chinese Film Since China's Reform and Openning-Up, CCTV 6, 19 November, 2018.

[22] Y. Liu, The Release and Influence of Japanese Films in China from the 1970s' to the 1980s', Hundred Schools in Arts, 24(06), 2008, pp. 186$189+193$. 